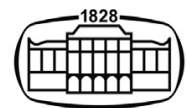

AKADÉMIAI KIADÓ

Journal of Behavioral Addictions

9 (2020) 1, 140-152

D01:

$10.1556 / 2006.2020 .00008$ (c) 2020 The Author(s)

\section{FULL-LENGTH REPORT}

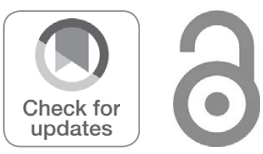

\title{
Response trajectories of gambling severity after cognitive behavioral therapy in young-adult pathological gamblers
}

\author{
ROSER GRANERO ${ }^{1,2}$, SUSANA VALERO-SOLIS ${ }^{3}$, \\ FERNANDO FERNÁNDEZ-ARANDA ${ }^{1,3,4}$, \\ MÓNICA GÓMEZ-PEÑA ${ }^{3}$, LAURA MORAGAS ${ }^{3}$, \\ TERESA MENA-MORENO ${ }^{3}$, AMPARO DEL PINO-GUTIERREZ ${ }^{5}$, \\ ESTER CODINA ${ }^{3}$, VIRGINIA MARTÍN-ROMERA ${ }^{6}$, \\ GEMMA CASALÉ ${ }^{3}$,ZAIDA AGÜERA ${ }^{1,3}$, ISABEL BAENAS-SOTO $^{3}$, \\ EDUARDO VALENCIANO-MENDOZA ${ }^{3}$, \\ BERNAT MORA-MALTAS ${ }^{3}$, ISABEL SÁNCHEZ ${ }^{3}$, \\ MARÍA LOZANO-MADRID ${ }^{3}$, JOSÉ M. MENCHÓN ${ }^{3,4,7}$ and \\ SUSANA JIMÉNEZ MURCIA ${ }^{1,3,4 *}$ ๑
}

\footnotetext{
${ }^{1}$ CIBER Fisiopatologia Obesidad y Nutrición (CIBERobn), Instituto de Salud Carlos III, Barcelona, Spain

${ }^{2}$ Departament de Psicobiologia i Metodologia, Autonomous University of Barcelona, Barcelona, Spain

${ }^{3}$ Department of Psychiatry, Bellvitge University Hospital-IDIBELL, Barcelona, Spain

${ }^{4}$ Department of Clinical Sciences, School of Medicine, University of Barcelona, Barcelona, Spain

${ }^{5}$ Department of Public Health, Mental Health and Mother-Infant Nursing, University School of Nursing, University of Barcelona, Barcelona, Spain

${ }^{6}$ Departamento de Educación y Psicología, Centro Universitario Cardenal Cisneros, Universidad de Alcalá, Madrid, Spain

${ }^{7}$ CIBER Salud Mental (CIBERsam), Instituto de Salud Carlos III, Barcelona, Spain
}

Received: September 7, 2019 • Revised manuscript received: November 28, 2019; January 21, 2020 - Accepted: January 25, 2020 • Published online: April 7, 2020

\footnotetext{
*Corresponding author. Department of Psychiatry, Bellvitge University Hospital-IDIBELL and CIBERObn, c/Feixa Llarga s/n, 08907, Hospitalet de Llobregat, Barcelona, Spain. Tel.: +349326079 88; fax: +3493 26076 58. E-mail: sjimenez@ bellvitgehospital.cat
}

\begin{abstract}
Background and aims: The significant increase in the prevalence of gambling disorder (GD) among young adults in recent years has attracted interest in determining therapeutic efficiency in this sector of the population. The aim of this work was to estimate the response trajectories of gambling severity during the six-month follow-up after a cognitive behavioral therapy (CBT) program in young adult patients and to identify the main variables associated with each trajectory. Methods: The sample included $n=192$ patients, aged 19-35 years old, seeking treatment for GD. Response trajectories were identified through latent class growth analysis. Results: Three trajectories emerged: T1 $(n=118,61.5 \%)$, composed of patients with severe GD at pre-treatment and good evolution to recovery; T2 $(n=62,32.3 \%)$, with patients with moderate-high GD affectation at baseline and good evolution to recovery; and T3 $(n=12,6.3 \%)$, with participants with severe baseline GD severity and poor evolution after CBT (Abbott, 2019). The highest risk of poor therapeutic outcomes was related to lower social index positions, high emotional distress, high scores in harm avoidance and low scores in self-directedness. Discussion and conclusions: Differences in the response trajectories at short-term follow-up after CBT reveal heterogeneity in the samples including young and young-adult GD patients. Patients' phenotype at baseline should be considered when developing efficient, person-centered intervention programs, which should comprise strategies aimed at increasing emotional regulation capacities, self-esteem and self-efficacy, with the aim of avoiding relapses in the medium-long term after therapy.
\end{abstract}

\section{KEYWORDS}

cognitive behavioral therapy, response trajectories, gambling disorder, latent class growth analysis, personality, psychological predictors 


\section{INTRODUCTION}

Gambling disorder (GD) is defined as the uncontrollable urge to continue gambling despite adverse consequences for the individuals (including impaired social functioning, financial trouble or even comorbidity of mental and physical diseases) (American Psychiatric Association, 2013). Recent systematic reviews show that GD problem behaviors are present in between 0.12 and $5.8 \%$ of the population across different countries worldwide (Calado \& Griffiths, 2016). Increasing prevalences have been estimated in recent decades in both sexes, with particularly disturbing incidences at increasingly younger ages (Calado, Alexandre, \& Griffiths, 2017; Gainsbury, Russell, Blaszczynski, \& Hing, 2015). This epidemiological picture has led researchers to consider GD as an emergent public health issue, with the consequent burgeoning of empirical research in approaches to preventing and treating gambling-related problems.

Similarities in the endophenotypes of substance-use disorders and GD have been systematically described, leading to craving, withdrawal, tolerance and abstinence syndrome (Banz, Yip, Yau, \& Potenza, 2016; Zou et al., 2017). Problem gambling is often accompanied by comorbid psychiatric and maladaptative personality traits, as well as dysfunction of cognitive domains regulating impulsive behavior (Ioannidis, Hook, Wickham, Grant, \& Chamberlain, 2019). The GD patients usually perceive multiple adverse consequences related to the gambling activity in several areas (biological, psychological, social and financial). Some individuals accept problematic gambling as a lifestyle and are unlikely to seek treatment (Babić et al., 2018), while others realize they have a problem, feel the need to control their urges to gamble and seek help to stop gambling and recover. Considering this scenario, empirical evidence is required for a better understanding of the underlying mechanisms related to the onset of problem gambling and the GD progression, with the aim of developing effective prevention programs addressed to highly vulnerable populations, to design reliable and valid tools to measure the complete profile of the GD, and to apply precise intervention plans focused on individuals' specific needs.

A number of studies to date have examined the effectiveness of different evidence-based treatment approaches for GD, such as cognitive behavioral therapy (CBT), participate in self-help groups, motivational interviewing, mindfulness, pharmaceutical treatments in certain cases, and novel mixed approaches (Petry, Ginley, \& Rash, 2017). Cognitive behavioral models have achieved good evidence explaining and managing GD related problems, and CBT is considered a "gold standard" for the treatment of GD (Abbott, 2019). A number of studies describe the model/ procedure of applying CBT in the field of substance-related disorders and behavioral addictions, such as the study by An and colleagues, which integrates key cognitive, affective and behavioral factors in differentiating phases/stages: antecedents, internal-external triggers, the act of the addictive behavior (such as gambling), and post-purchase states (An, He, Zheng, \& Tao, 2017). Based on this model, GD can be depicted in the form of a vicious circle, whereby the final negative post-purchase stage generates the emotional triggers for the repetition of the whole cycle, which allows for GD to become self-reinforcing/regulating over time. CBT programs are focused on the development and maintenance of coping strategies that target solving current problems and changing unhelpful patterns in cognitive, behavioral and emotional regulation, with the aim of identifying and acting on the elements supporting the vicious circle around the gambling behavior. Accordingly, CBT includes the development of skills for learning to control and manage highrisk situations to effectively reduce the probability of gambling in the future and to prevent relapses. Compared to substance addictions, the CBT treatment adapted to GD may target the addictive behavior, its underlying mechanisms (including irrational cognitions), and financial management (including potential financial problems) (Rash \& Petry, 2014).

A wide variety of CBT programs have been developed for GD. Most of them include common elements, such as systematic desensitization, stimulus control, psychoeducation, financial counseling, cognitive restructuring techniques, and relapse prevention. As a whole, recent systematic reviews measuring the effectiveness of these programs maintain that $\mathrm{CBT}$ is an efficient intervention plan at reducing gambling problems and related symptoms immediately following therapy, while the durability of the therapeutic usefulness is unknown (Cowlishaw et al., 2012; Merkouris, Thomas, Browning, \& Dowling, 2016). But research gaps exist, as well as controversies regarding how CBT works in the treatment of problem gambling, which particular CBT programs are the most effective, and what is the real usefulness of the different CBT modalities depending on the GD profiles at baseline (Gooding \& Tarrier, 2009; Tolchard, 2017). Studies focused on identifying the main factors contributing to both the effectiveness and poor outcome of CBT in GD patients have also obtained varied results. As a whole, high dropout and relapse rates (during the therapy program and in the follow-up), as well as non-compliance issues, are common in outpatient programs (Aragay et al., 2015; Challet-Bouju, Bruneau, IGNACE Group, Victorri-Vigneau, \& GrallBronnec, 2017). The most significant contributors to limiting long-term adverse consequences and improving outcome appear to be early identification, low severity of gambling at baseline, low severity of psychopathological comorbidity, high motivation, and some personality domains related to impulsivity (Dunn, Delfabbro, \& Harvey, 2012). Male gender, low comorbid depression levels, lower gambling symptom severity and higher treatment session attendance have also been found to be the most likely and consistent predictors of successful treatment outcomes across multiple time points (post-treatment, short term, medium term and long term) (Gómez-Peña et al., 2012; S. Jiménez-Murcia et al., 2016, 2015; Merkouris et al., 2016). The resistance to CBT found in many studies has also led to considering the inclusion of supplementary strategies to improve emotional regulation and decrease impulsivity levels in therapeutic plans, with promising therapeutic 
effectiveness (Mallorquí-Bagué et al., 2018; Peter et al., 2019; Tárrega et al., 2015).

Parallel to the study of the therapy outcomes, research has focused on the classification of the subtypes of GD and its correlates. It is well known that numerous factors contribute to the risk of developing diverse gambling problems, such as the presence of emotional distress, early wins, cognitive biases related to the gambling activity, impulsivity, personality traits and some sociodemographic features. Different underlying mechanisms have also been related to the onset and courses of the problem gambling. Subtyping GD could also contribute with new valuable evidence toward precise interventions to match individuals' needs. The three pathways model proposed by Blaszczynski and Nower is nowadays one of the most referenced classification systems, considered as a multi-causal framework for conceptualizing GD on the basis of three subtypes of pathological gamblers (Blaszczynski \& Nower, 2002): behavioral conditioned (the onset of the disorder resulted from repeated exposure to gambling and the course of the problems was consequence of the contingencies related to the gambling activity), emotionally vulnerable (the patients use the gambling activity as a way to relieve aversive affective states) and antisocial-impulsive (patients with high levels of emotional dysregulation, impulsivity and neurological dysfunction). Subsequent research has examined the validity of this three pathways model in samples with diverse composition and considering different measures for the definition of the latent classes. For example, Milosevic and Ledgerwood identified three GD subtypes (with differences in the psychopathology state, the personality traits and the motivations for gambling) in a comprehensive review of the available empirical literature, and concluded that these profiles were parallel to the three types of gamblers defined in the pathways model (Milosevic \& Ledgerwood, 2010). The subsequent study conducted by Moon and colleagues also provided evidence for the validity of the three pathways model as a framework for conceptualizing GD subtypes in a sample comprising both non-treatment-seeking individuals and pathological disordered gamblers, through a hierarchical cluster analysis examining motives for the gambling activity: childhood trauma, boredom proneness, risk-taking, impulsivity, attention-deficit/hyperactivity disorder and antisocial personality (Moon, Lister, Milosevic, \& Ledgerwood, 2017). The research by Nower et al. derived three empirical subtypes of disordered gamblers roughly corresponding to the subtypes of the three pathways model, ranging from a subgroup with a lower level of gambling activity and psychopathology to one with high levels of gambling problem severity and comorbid psychiatric disorders (Nower, Martins, Lin, \& Blanco, 2013). Finally, the recent study by Devos and colleagues conducting a classification analysis using impulsivity traits and gambling-related cognitions as indicators, also identified three clusters aligned with the three pathways model among a sample composed of gamblers recruited from the community and treatment-seeking pathological gamblers (Devos et al., 2020). But to our knowledge, few studies have examined how the putative subtypes of GD obtain benefits from the CBT programs. The research conducted by Ledgerwood and Petry aimed at obtaining a categorization based on the scores in anxiety, depression and impulsivity observed that although the three pathways types differed in some baseline measures [gambling level, emotional impairment, or the presence of other comorbid disorders (concurrent and lifespan)], this classification did not obtain predictive capacity on the gambling severity after the treatment (Ledgerwood \& Petry, 2010). Further studies exploring GD subtypes based on the problem gambling severity through treatments and followup should reveal different patterns of recovery and therefore contribute towards identifying the most relevant predictors of the outcomes and the progression of the gambling profiles.

\section{Present study}

Despite the available evidence reinforcing the effectiveness of CBT across varied GD patients, increased attention needs to be given to the diverse populations and phenotypes, to the mechanisms of change, medium- and long-term outcomes, and predictors of relapse prevention. In addition, there is no single conceptual/theoretical model of the GD subtyping that adequately accounts for the multiple factors explaining the onset of the gambling problems, its progression and the benefit of the CBT programs.

To our knowledge, no study to date has addressed CBT outcomes in young and young-adult GD patients. The main objective of this study is to use growth curve modeling to estimate response trajectories of the GD progression during the short-term follow-up (6 months) after a group CBT treatment in a sample of young and young-adult GD patients. The secondary objective is to assess the discriminative capacity of sociodemographic and clinical profiles at baseline to differentiate between empirical trajectories.

\section{METHODS}

\section{Participants}

The sample of this study considered all the consecutive treatment-seeking patients attending one hospital unit specializing in GD and other behavioral addictions in Barcelona (Spain), who fulfilled the following inclusion criteria: fulfill diagnostic criteria for GD, male gender and chronological age within the range of 18 to 35 years old. Exclusion criteria were having an intellectual disability or severe mental disorder (such as schizophrenia or other psychotic disorders or bipolar disorder). Women were also excluded from this work because their low frequency in the treatment unit and the specific GD profiles in women made it more appropriate individual CBT programs (instead the group CBT format analyzed in this work).

The age range from 18 to 35 years was considered as an inclusion criterion since the aim of the study was to obtain empirical trajectories for the therapy response after CBT among middle-age patients. Although there is no complete 
consensus regarding the boundary limits for considering young-, middle- and older-age in the health sciences, many studies carried out in the problem gambling area consider that this is the period from late adolescence (age 18 corresponds to legal adulthood) to one's late twenties or early thirties. Prevalence studies internationally have reported that individuals in this age group tend to have the highest rates of problem gambling, and have usually chosen 35 years of age as an upper bound limit (Grande-Gosende, López-Núñez, García-Fernández, Derevensky, \& Fernández-Hermida, 2019; Petry, 2002).

The final sample of participants included $n=192$ participants who completed the CBT program, with a mean chronological age of 29.7 years $(S D=4.1)$ and a mean age of onset of the GD of 21.1 years $(\mathrm{SD}=4.7)$. Many participants were single $(n=112,58.2 \%)$, had a primary $(n=83,43.2 \%)$ or secondary $(n=95,49.5 \%)$ education level, and held mean-low $(n=78,40.6 \%)$ or low $(n=68,35.4 \%)$ socioeconomic levels. The first two columns in Table 2 contain the frequency distributions for all the variables analyzed in the study for the whole sample.

The number of dropouts during the follow-up was $n=55$ : risk of dropout $=28.6 \%$, a value consistent with prospective studies carried out in the gambling area (Challet-Bouju et al., 2017). No statistical differences in the sociodemographics and the clinical state at baseline were found comparing patients who completed all the follow-up versus those who dropped out (sex: $\chi_{(d f=2)}^{2}=2.77, P=.251$; education: $\chi_{(d f=2)}^{2}=1.22$, $P=0.543$; socioeconomic position index: $\chi_{(d f=3)}^{2}=2.82$, $P=0.420$, employment status: $\chi_{(d f=2)}^{2}=0.03, P=0.863$, chronological age: $F_{(d f=1 ; 190)}=0.76, P=0.385$, age of onset of the gambling problems: $F_{(d f=1 ; 190)}=1.10, P=0.297$, duration of the gambling problems: $F_{(d f=1 ; 190)}=2.07, P=0.152$, number of DSM-5 criteria for GD: $F_{(d f=1 ; 190)}=0.51, P=$ 0.478 , SOGS total score: $F_{(d f=1 ; 190)}=1.54, P=0.216$, and SCL-90R GSI: $\left.F_{(d f=1 ; 190)}=0.57, P=0.540\right)$.

\section{Measures}

Diagnostic Questionnaire for Pathological Gambling According to DSM Criteria (Stinchfield, 2003). This is a 19-item tool for assessing DSM-IV (American Psychiatric Association, 2000) criteria for GD, as well as the DSM-5 (American Psychiatric Association, 2013) criteria for this clinical condition. The original version achieved good psychometric properties, as did the Spanish adaptation used in this study (S. Jiménez-Murcia et al., 2009). In our sample, the internal consistency was adequate (Cronbach's alpha $\alpha=0.75$ ).

South Oaks Gambling Screen (SOGS) (Lesieur \& Blume, 1987). This instrument is a common tool to assess GD severity, structured in 20 items that measure cognitive, emotional and other behavior strongly related to gambling problems. The Spanish adaptation of this tool showed good high internal consistency (Cronbach's alpha $\alpha=0.94$ ) and good test-retest reliability $(r=0.98)$ (Echeburúa, Báez, Fernández, \& Páez, 1994). In our sample, internal consistency was adequate $(\alpha=0.79)$.
Symptom Checklist-90 Items-Revised (SCL-90-R) (Derogatis, 1994). This instrument is a self-report tool used for measuring global psychopathology through 90 items structured in nine symptom dimensions (obsessive-compulsive, depression, anxiety, hostility, interpersonal sensitivity, phobic anxiety, somatization, paranoid ideation and psychoticism) and three composite indexes [the global severity index (GSI), the positive symptom total, and the positive symptom distress index]. Good psychometric properties have been reported in Spanish samples (Derogatis, 1997). In our study, the GSI index was employed as a measure of global psychopathology, with an excellent internal consistency in our sample equal to $\alpha=0.97$.

Temperament and Character Inventory-Revised (TCI-R) (C R Cloninger, 1999). This instrument is a 240-item tool for measuring personality, structured in four temperament dimensions (novelty seeking, harm avoidance, reward dependence and persistence) and three character scales (cooperativeness, self-directedness and self-transcendence). The adapted Spanish version has reported good psychometric indexes (Gutiérrez-Zotes et al., 2004). In our sample, internal consistency ranged from adequate to excellent ( $\alpha=$ 0.72 for novelty seeking to $\alpha=0.88$ for persistence).

Other sociodemographic and clinical variables. Additional data were obtained through a semi-structured face-to-face clinical interview (see description in: (Susana JiménezMurcia, Aymamí, Gómez-Peña, Álvarez-Moya, \& Vallejo, 2006)). The main addictive-related variables analyzed in this study are the age of GD onset, the duration of the addiction, and social status (measured through Hollingshead's index) (Hollingshead, 2011).

\section{CBT program}

In the present study, CBT was implemented as a time-limited technique of 16 weekly sessions lasting 90 minutes each, in group (averaging approximately 10 patients per group). The final aims were to achieve full recovery (defined as the definitive abstinence from all types of gambling), to reduce patients' arousal levels in the presence of stimuli that trigger the urge to gamble, to increase their self-control, to regulate their negative emotions and to improve their self-efficacy and their expectations of recovery. The full protocol is available directly from the corresponding author of the manuscript.

Patients received the protocols CBT outpatient program in the Hospital Unit. The program was presented and developed by a qualified CBT, a clinician expert on problematic gambling and GD. Prior to the beginning of the program, patients received group psychoeducation focused on the following topics: a) conceptualization of the GD (providing knowledge about the endophenotype, the onset and course/progression of the disorder, and vulnerability and protective factors); b) explaining the rationale behind CBT; c) patients learning to identify their dysfunctional thoughts and feelings related to the gambling activity; d) explaining problem-solving techniques and cognitive restructuring techniques to generate alternative functional thoughts and feelings of wellbeing (including relaxation procedures); and e) patients learning stimulus control 


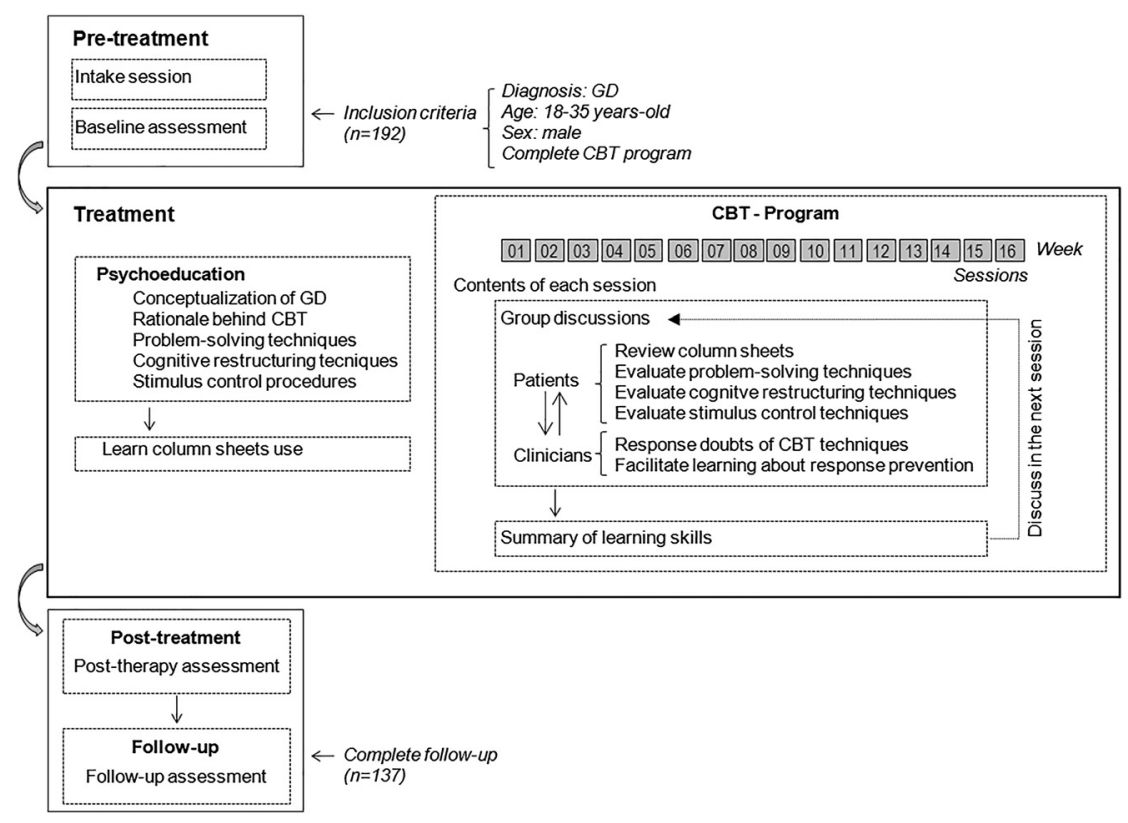

Figure 1. Flowchart/scheme with the CBT program in the study

procedures [such as money management, self-exclusion (from both land-based and online gambling) and avoidance of potential triggers]. Patients were also encouraged to ask a close relative (or significant other) to act as a co-therapist, to help them with all the relapse prevention techniques.

Prior to the CBT program, participants also received column sheets to complete (daily completion is required). Columnar sheets included the following topics: situations where participants felt unwell (sad, anxious, irritable), behaviors related to gambling, automatic thoughts, an objective examination of those automatic thoughts (including counterevidence), adaptive thoughts, and changes in feeling and behavior.

During the 16 treatment sessions, patients applied CBT techniques, completed the column sheets and held group discussions by exchanging questions and opinions regarding the progression of the therapy (mainly, they review the column sheets, evaluate the cognitive restructuring techniques and discussed problem-solving techniques). The clinicians reviewed the column sheets providing contextual explanations and advice on the column methods to complete them during the following weeks. Participants also improved their understanding of the cognitive restructuring and problem-solution techniques by consulting with the CBT clinician expert any doubts regarding response prevention techniques. A summary of the learned skills during CBT was also given in each session. Within approximately four months the CBT program is completed.

After the CBT program, and over the next 6 months, follow-up sessions were held with the patients. The changes in the gambling behavior and in the whole psychological state, as well as the learned skills, were evaluated in the follow-up.

Figure 1 with the flowchart/scheme of the CBT program in the study. Different studies have shown its short- and long-term effectiveness in GD samples (S. Jiménez-Murcia et al., 2017; Susana Jiménez-Murcia et al., 2007, 2016, 2015).

\section{Procedure}

Psychological measures were obtained by experienced psychologists with more than 15 years of clinical knowledge of this disorder.

The data analyzed in this work correspond to a longitudinal design comprising the assessment before the start of the CBT program, immediately following CBT, and monthly during the 6 months period following the program.

\section{Statistical analyses}

Mplus8 for Windows was used to perform the study's statistical analyses, which combined two different approaches: person-centered and variable-centered procedures. Personcentered methods are typically used to identify groups of individuals who share some specific attributes (characteristics) and to address questions related to group similarities in patterns of development/courses. In contrast, variablecentered approaches are classical methodological procedures used to describe the associations between variables and are suited for addressing the relative contribution of the independent features (predictors) on the dependent outcomes (criteria). In this work, the person-centered approach was implemented through response trajectories analysis and was employed to determine if subgroups of patients exist based on the prospective dynamics of GD severity after the therapeutic intervention and, in such cases, empirically categorizing the individuals into common classes. Next, after establishing the response trajectories, these empirical groups ("latent classes") were compared through variable-centered methods with the aim of assessing how sociodemographic and clinical variables predict GD severity trajectories. 
Latent class growth analysis (LCGA) was employed to obtain the empirical GD response trajectories based on gambling severity between post-treatment and 6 months after the final intervention. LCGA is a model included within growth-mixture-modeling (GMM) techniques, characterized by fixing to zero the variance/covariance estimates within a class under the assumption that individuals grouped in the class are homogeneous. Methods used in this study were conducted following GRoLTS guidelines (van de Schoot, Sijbrandij, Winter, Depaoli, \& Vermunt, 2017). The trajectories were estimated for the variable SOGS-total score (considered in this research as a measure of gambling problem severity) registered during the first 6 months after completion of the CBT program (seven measurements per participant were used for the grouping: the post-treatment assessment and the next 6 monthly post-evaluations). Because of the strong association between the decreases in problem severity and the initial (baseline) state, the estimation procedure included baseline SOGS-total as a covariate. The GMM was employed (TYPE = MIXTURE, in Mplus syntax), defining the robust maximum likelihood (MLR) estimator in the Analysis command (Enders \& Bandalos, 2001; Graham, 2009) and using Lo-Mendell-Rubin (Lo, Mendell, \& Rubin, 2001) as a measure to determine the number of classes. The selection of the number of trajectories was based on the following criteria (Nylund, Asparouhov, \& Muthén, 2007): a) the lowest Akaike information criterion (AIC), Bayesian information criterion (BIC), Lo-MendellRubin adjusted likelihood ratio test (LMR-LRT) and the bootstrapped likelihood ratio test (BLRT) indexes for the model (compared with other solutions); b) entropy (measure of the model's discriminative capacity, that is, its ability to identify individuals following the different trajectories) above 0.80 ; c) high on-diagonal average values (around 0.80 ) in the matrix containing the probabilities of membership (that is, high average latent class probabilities for most likely latent class membership by latent class); d) no less than $5 \%$ of participants in a class/trajectory (to allow statistical comparisons); and e) adequate clinical interpretability. The estimation procedure was defined for a linear growth model based on the principle of parsimony (other alternative, more complex quadratic and cubic components were tested and rejected since these other potential solutions did not provide substantively better statistical adjustment and/or models with better clinical interpretation).

Comparison between the empirical latent classes (the response trajectories in this work) was based on chi-square tests for categorical variables (Fisher-exact tests were used for comparisons with cells with low expected frequencies, $\left.e_{\mathrm{ij}}<5\right)$ and analysis of variance (ANOVA) for quantitative variables. Variables compared included measures at baseline (chronological age, age of onset of the gambling, duration of the gambling, DSM-5 criteria for GD, SOGS total score, psychopathological state and personality traits) as well as the presence of relapses during the CBT (relapse was defined as the presence of any gambling episode during which the patients make some kind of bet). The effect size for pairwise comparisons was calculated with Cohen's $d$ for mean differences and Cohen's $h$ for proportion differences ( $h$-coefficients were based on the arcsine transformations for the proportions estimated in the groups). The effect size was considered poor-low for $|d|>0.20$, mild-moderate for $|d|>0.50$ and large-high for $|d|>0.80$ (the same boundary limits were considered in interpreting $h$-coefficients) (Kelley \& Preacher, 2012). Increases in Type-I errors due to multiple statistical comparisons were controlled with Simes' correction method, a familywise error rate stepwise procedure that offers a more powerful test than the classical Bonferroni correction (Simes, 1986).

\section{Ethics}

The study procedures were carried out in accordance with the Declaration of Helsinki. The University Hospital of Bellvitge's Ethics Committee of Clinical Research approved the study (reference: PR241/11), and all patients provided signed informed consent.

\section{RESULTS}

Table 1 contains the goodness-of-fit indexes for the candidate models obtained in the LCGA, with a number of trajectories between 1 and 4 latent classes (trajectories). Solution models for more than three classes were not considered due to the small group size to allow for subsequent statistical comparisons (the four-classes model defined a group with only two participants).

The final model selected was the three-trajectory solution (Fig. 2 shows the line graph with the shapes for the SOGS evolution from the pre-therapy measure to the 6-month follow-up after the CBT). This model yielded lower AIC-BIC indexes than the two-trajectory solution ( $\mathrm{AIC}=4159.5$, $\mathrm{BIC}=4247.4$ and adjusted sample-size $\mathrm{BIC}=4161.9)$, good entropy (0.846), very high on-diagonal values in the matrix with the average latent class probabilities $(0.951,0.898$, and 0.944 for trajectories T1, T2, and T3), and good clinical interpretability.

Table 2 includes the comparison between trajectories for the variables analyzed in this study (sociodemographic variables are reported in the upper part of the table, baseline state in the middle portion and the risk of relapse during the CBT in the lower part). Trajectory T1 $(n=118,61.5 \%)$ included patients with severe GD level at baseline (mean SOGS $=12.5$ ) and good evolution to recovery (mean SOGS $=2.6$ at post-therapy and 2.4 at the end of the follow-up).

Trajectory T2 $(n=62,32.3 \%)$ represented patients with moderate-high GD affectation at baseline (mean SOGS $=8.7$ ) and good evolution to recovery (mean SOGS $=2.1$ at the end of the therapy and 2.3 at the end of the study). The progression of the gambling severity for this response trajectory is quite similar to trajectory $\mathrm{T} 1$, and no statistical differences between $\mathrm{T} 1$ and $\mathrm{T} 2$ emerged comparing sociodemographics, chronological age and age of onset of the gambling problems. However, compared to T1, participants grouped in T2 
Table 1. Goodness-of-fit indexes for the LCGA candidate solutions

\begin{tabular}{|c|c|c|c|c|c|c|c|c|c|c|}
\hline \multirow{2}{*}{$\begin{array}{l}\text { Model } \\
\mathrm{e}_{\# \text { Traj. }}\end{array}$} & \multicolumn{6}{|c|}{ Fit indexes } & & \multicolumn{2}{|c|}{ Count-size } & \multirow{2}{*}{$\begin{array}{l}{ }^{\mathrm{d}} \mathrm{On}-\mathrm{d} . \\
\text { post.prob. }\end{array}$} \\
\hline & Akaike AIC & Bayes BIC & ${ }^{\mathrm{a}}$ Adj. BIC & ${ }^{\mathrm{b}} \mathrm{LMR}-\mathrm{LRT}$ & ${ }^{\mathrm{c} B o o s t}$ BLRT & Entropy & & $n$ & $\%$ & \\
\hline $1-\mathrm{Tr}$ & 4397.8 & 4446.6 & 4399.1 & - & - & 1.00 & $\mathrm{~T} 1$ & 192 & $100 \%$ & 1.000 \\
\hline \multirow[t]{2}{*}{$2-\operatorname{Tr}$} & 4231.6 & 4300.0 & 4233.5 & 172.7 & -2183.9 & 0.954 & $\mathrm{~T} 1$ & 179 & $93.2 \%$ & 0.994 \\
\hline & & & & $(0.073)$ & $(<0.001)$ & & $\mathrm{T} 2$ & 13 & $6.8 \%$ & 0.935 \\
\hline \multirow[t]{3}{*}{$3-\operatorname{Tr}$} & 4159.5 & 4247.4 & 4161.9 & 81.53 & -2094.8 & 0.846 & $\mathrm{~T} 1$ & 118 & $61.5 \%$ & 0.951 \\
\hline & & & & $(0.067)$ & $(<0.001)$ & & $\mathrm{T} 2$ & 62 & $32.3 \%$ & 0.898 \\
\hline & & & & & & & T3 & 12 & $6.3 \%$ & 0.944 \\
\hline \multirow[t]{4}{*}{$4-\mathrm{Tr}$} & 4063.9 & 4171.4 & 4066.8 & 80.76 & -2040.2 & 0.802 & $\mathrm{~T} 1$ & 117 & $60.9 \%$ & 0.931 \\
\hline & & & & $(0.064)$ & $(<0.001)$ & & $\mathrm{T} 2$ & 57 & $29.8 \%$ & 0.894 \\
\hline & & & & & & & $\mathrm{T} 3$ & 16 & $8.3 \%$ & 0.872 \\
\hline & & & & & & & $\mathrm{T} 4$ & 2 & $1.0 \%$ & 0.999 \\
\hline
\end{tabular}

${ }^{\mathrm{a}}$ Sample-size adjusted BIC.

${ }^{\mathrm{b}}$ Lo-Mendell-Rubin adjusted likelihood ratio test: test value (significance, $P$-value).

${ }^{\mathrm{c}}$ Bootstrapped likelihood ratio test (BLRT): Log-likelihood value (significance, $P$-value).

${ }^{\mathrm{d}}$ On-diagonal posterior average values in the matrix containing the probability of membership.

${ }^{\mathrm{e}}$ Number of trajectories.

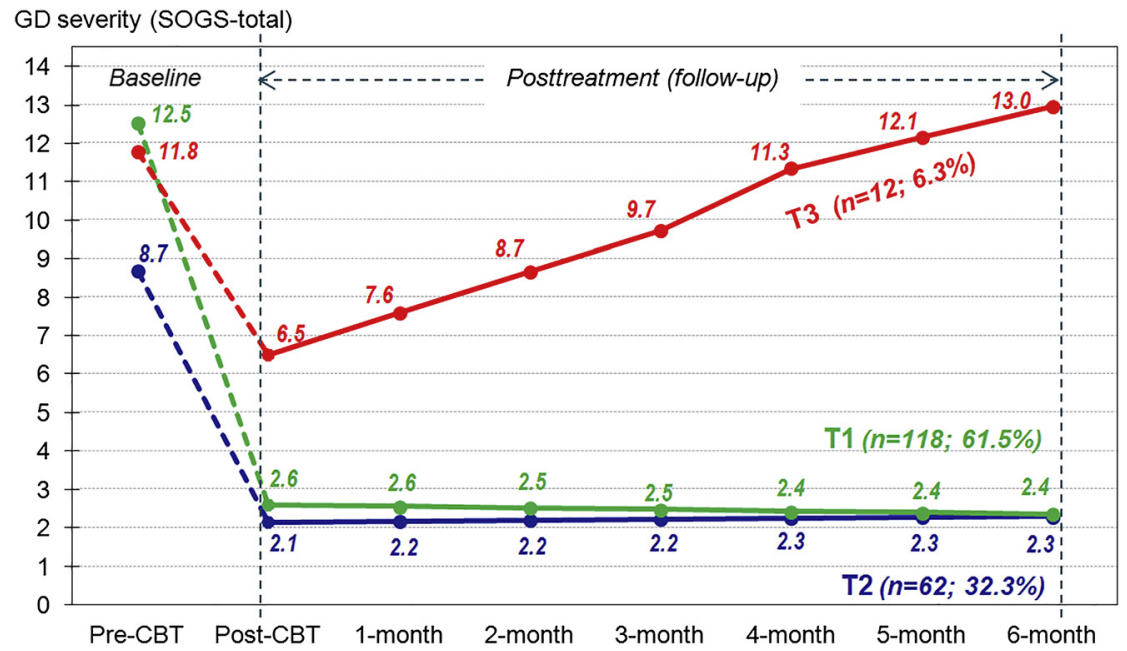

Figure 2. Response trajectories: from pretreatment to 6-month follow-up after therapy $(n=192)$

registered lower values in novelty seeking and harm avoidance, higher scores in persistence, self-directedness and cooperativeness, more functional psychopathological state (lower SCL-90R GSI score), lower GD severity at pre-treatment and lower evolution of the gambling problems prior to the therapy.

Trajectory T3 $(n=12,6.3 \%)$ represented patients with severe GD affectation at baseline (mean SOGS $=11.8$ ) and poor evolution after the CBT (mean SOGS $=6.5$ at posttherapy and 13.0 at 6-month follow-up after the treatment). Based on the descriptive estimations, this trajectory included participants with the worst psychopathological state at the beginning of the study (although no significant difference was found between T1 and T3 in the SCL-90R GSI), the highest harm avoidance levels and the lowest self-directedness scores. This trajectory also included a high proportion of participants in the low education levels and low socioeconomic status groups, and it registered the highest risk of relapses (calculated as the probability of occurrence of any gambling episode with bets) during the therapy (33.3\% versus $16.1 \%$ registered for $\mathrm{T} 1$ and $14.5 \%$ for $\mathrm{T} 2$ ).

\section{DISCUSSION}

The main objective of the study was to identify empirical response trajectories for GD severity during the 6-month follow-up after CBT in young and young-adult patients through LCGA. Three trajectories emerged, two of them comprising patients with moderate to severe GD affectation at baseline and good evolution to recovery (T1 and T2 included the largest number of patients, $n=250,93.7 \%$ of the whole sample) and one containing patients with severe baseline GD severity and poor CBT outcome (T3 included $n=12,6.3 \%$ of the sample). The goodness of fit and the clinical interpretability of the results constitute evidence about the reliability and validity of the response trajectories. 
Table 2. Comparison between empirical response trajectories

\begin{tabular}{|c|c|c|c|c|c|c|c|c|c|c|c|c|c|c|c|c|c|}
\hline \multirow[b]{3}{*}{ Sociodemographics } & \multirow{3}{*}{$\alpha$} & \multirow{2}{*}{\multicolumn{2}{|c|}{$\begin{array}{c}\text { Total } \\
N=192\end{array}$}} & \multirow{2}{*}{\multicolumn{2}{|c|}{$\begin{array}{c}\mathrm{T} 1 \\
n=118\end{array}$}} & \multirow{2}{*}{\multicolumn{2}{|c|}{$\begin{array}{c}\mathrm{T} 2 \\
n=62\end{array}$}} & \multirow{2}{*}{\multicolumn{2}{|c|}{$\frac{\mathrm{T} 3}{n=12}$}} & \multirow{2}{*}{\multicolumn{2}{|c|}{$\frac{\text { Global comparison }}{\text { (Factor group) }}$}} & \multicolumn{6}{|c|}{ Pairwise comparisons } \\
\hline & & & & & & & & & & & & \multicolumn{2}{|c|}{ T1vsT2 } & \multicolumn{2}{|c|}{ T1vsT3 } & \multicolumn{2}{|c|}{ T2vsT3 } \\
\hline & & $n$ & $\%$ & $n$ & $\%$ & $n$ & $\%$ & $n$ & $\%$ & $\chi_{(d f)}^{2}$ & $P$ & $P$ & $|h|$ & $P$ & $|h|$ & $P$ & $|h|$ \\
\hline \multicolumn{18}{|l|}{ Marital status } \\
\hline Single & & 112 & $58.3 \%$ & 70 & $59.3 \%$ & 34 & $54.8 \%$ & 8 & $66.7 \%$ & $1.99(4)$ & 0.738 & 0.600 & 0.09 & 0.537 & 0.15 & 0.664 & 0.24 \\
\hline Married-partner & & 71 & $37.0 \%$ & 44 & $37.3 \%$ & 24 & $38.7 \%$ & 3 & $25.0 \%$ & & & & 0.03 & & 0.27 & & 0.30 \\
\hline Separated-divorce & & 9 & $4.7 \%$ & 4 & $3.4 \%$ & 4 & $6.5 \%$ & 1 & $8.3 \%$ & & & & 0.14 & & 0.21 & & 0.07 \\
\hline \multicolumn{18}{|l|}{ Education } \\
\hline Primary & & 83 & $43.2 \%$ & 47 & $39.8 \%$ & 29 & $46.8 \%$ & 7 & $58.3 \%$ & $3.39_{(4)}$ & 0.080 & 0.458 & 0.14 & 0.333 & 0.38 & 0.621 & 0.23 \\
\hline Secondary & & 95 & $49.5 \%$ & 60 & $50.8 \%$ & 30 & $48.4 \%$ & 5 & $41.7 \%$ & & & & 0.05 & & 0.18 & & 0.14 \\
\hline University & & 14 & $7.3 \%$ & 11 & $9.3 \%$ & 3 & $4.8 \%$ & 0 & $0.0 \%$ & & & & 0.18 & & $0.51^{\dagger}$ & & 0.32 \\
\hline \multicolumn{18}{|l|}{ Social } \\
\hline Mean-high + high & & 17 & $8.9 \%$ & 11 & $9.3 \%$ & 6 & $9.7 \%$ & 0 & $0.0 \%$ & $3.94_{(6)}$ & 0.214 & 0.656 & 0.01 & 0.488 & $0.51^{\dagger}$ & 0.575 & $0.51^{\dagger}$ \\
\hline Mean & & 29 & $15.1 \%$ & 21 & $17.8 \%$ & 7 & $11.3 \%$ & 1 & $8.3 \%$ & & & & 0.19 & & 0.28 & & 0.10 \\
\hline Mean-low & & 78 & $40.6 \%$ & 45 & $38.1 \%$ & 28 & $45.2 \%$ & 5 & $41.7 \%$ & & & & 0.14 & & 0.07 & & 0.07 \\
\hline Low & & 68 & $35.4 \%$ & 41 & $34.7 \%$ & 21 & $33.9 \%$ & 6 & $50.0 \%$ & & & & 0.02 & & 0.31 & & 0.33 \\
\hline \multicolumn{18}{|l|}{ Laboral status } \\
\hline Unemployed & & 47 & $24.5 \%$ & 28 & $23.7 \%$ & 16 & $25.8 \%$ & 3 & $25.0 \%$ & $0.10_{(2)}$ & 0.953 & 0.758 & 0.05 & 0.922 & 0.03 & 0.953 & 0.02 \\
\hline Baseline state & & Mean & $S D$ & Mean & $S D$ & Mean & $S D$ & Mean & $S D$ & $F_{(d f)}$ & $P$ & $P$ & $|d|$ & $P$ & $|d|$ & $P$ & $|d|$ \\
\hline Age (years) & & 29.68 & 4.07 & 29.97 & 3.85 & 29.10 & 4.34 & 29.83 & 4.82 & $0.94_{(2 ; 189)}$ & 0.394 & 0.175 & 0.21 & 0.914 & 0.03 & 0.567 & 0.16 \\
\hline Age onset (years) & & 21.10 & 4.70 & 20.70 & 4.36 & 21.77 & 5.04 & 21.62 & 6.05 & $1.06_{(2 ; 189)}$ & 0.349 & 0.141 & 0.23 & 0.501 & 0.18 & 0.937 & 0.03 \\
\hline Duration (years) & & 9.78 & 5.30 & 10.48 & 5.23 & 8.54 & 5.22 & 9.18 & 5.67 & $2.66_{(2 ; 189)}$ & 0.073 & $0.024^{\star}$ & 0.37 & 0.436 & 0.24 & 0.712 & 0.12 \\
\hline DSM-5 total criteria & 0.75 & 7.14 & 1.63 & 8.04 & 0.85 & 5.23 & 1.14 & 8.17 & 0.83 & $185.3_{(2 ; 189)}$ & $<0.001^{*}$ & $<0.001^{*}$ & $2.80^{\dagger}$ & 0.667 & 0.15 & $<0.001^{*}$ & $2.95^{\dagger}$ \\
\hline SOGS-total score & 0.79 & 11.27 & 2.98 & 12.58 & 2.41 & 8.70 & 2.38 & 11.67 & 2.12 & $52.8_{(2 ; 189)}^{6}$ & $<0.001^{*}$ & $<0.001^{\star}$ & $1.62^{\dagger}$ & 0.270 & 0.40 & $0.001^{*}$ & $1.31^{\dagger}$ \\
\hline Psychopology SCL-90R: GSI & 0.97 & 0.87 & 0.55 & 0.99 & 0.56 & 0.57 & 0.39 & 1.21 & 0.66 & 15.5 & $<\mathbf{0 . 0 0 1}^{\star}$ & $<\mathbf{0 . 0 0 1}^{\star}$ & $\mathbf{0 . 8 8 ^ { \dagger }}$ & 0.219 & 0.36 & $0.001^{*}$ & $1.18^{\dagger}$ \\
\hline Personality (TCI-R) & & Mean & $S D$ & Mean & $S D$ & Mean & $S D$ & Mean & $S D$ & $F_{(d f)}$ & $P$ & $P$ & $|d|$ & $P$ & $|d|$ & $P$ & $|d|$ \\
\hline Novelty seeking & 0.72 & 112.4 & 13.8 & 115.1 & 14.2 & 106.9 & 11.6 & 113.3 & 12.5 & $7.56_{(2 ; 189)}$ & $0.001^{\star}$ & $<0.001^{\star}$ & $0.63^{\dagger}$ & 0.658 & 0.13 & 0.129 & $\mathbf{0 . 5 3} 3^{\dagger}$ \\
\hline Harm avoidance & 0.83 & 97.3 & 16.9 & 98.2 & 16.7 & 93.2 & 16.4 & 109.3 & 15.1 & $5.20_{(2 ; 189)}$ & $0.006^{*}$ & $0.047^{\star}$ & 0.30 & $0.028^{*}$ & $\mathbf{0 . 7 0 ^ { \dagger }}$ & $0.002^{\star}$ & $1.02^{\dagger}$ \\
\hline Reward dependence & 0.78 & 98.7 & 14.3 & 97.7 & 14.4 & 100.9 & 13.9 & 97.8 & 15.6 & $1.01_{(2 ; 189)}$ & 0.364 & 0.161 & 0.23 & 0.969 & 0.01 & 0.503 & 0.21 \\
\hline Persistence & 0.88 & 109.9 & 19.7 & 108.2 & 20.9 & 114.1 & 16.2 & 105.2 & 21.9 & $2.13_{(2 ; 189)}$ & 0.121 & $0.050^{\star}$ & 0.31 & 0.606 & 0.14 & 0.152 & $0.56^{\dagger}$ \\
\hline Self-directedness & 0.86 & 128.4 & 20.5 & 124.5 & 19.3 & 139.5 & 18.8 & 111.1 & 13.4 & $17.93_{(2 ; 189)}$ & $<0.001^{\star}$ & $<0.001^{\star}$ & $0.79^{\dagger}$ & $0.020^{*}$ & $0.80^{\dagger}$ & $<0.001^{\star}$ & $1.74^{\dagger}$ \\
\hline Cooperativeness & 0.81 & 130.4 & 15.5 & 128.0 & 15.5 & 136.4 & 13.7 & 123.7 & 15.9 & $7.47_{(2 ; 189)}$ & $0.001^{\star}$ & 0.001 & $0.57^{\dagger}$ & 0.341 & 0.28 & $0.008^{*}$ & $\mathbf{0 . 8 6} 6^{\dagger}$ \\
\hline Self-transcendence & 0.80 & 59.9 & 12.9 & 59.5 & 12.9 & 59.6 & 12.7 & 65.6 & 13.5 & $1.23_{(2 ; 189)}$ & 0.293 & 0.986 & 0.00 & 0.123 & 0.45 & 0.142 & 0.46 \\
\hline During CBT & & $n$ & $\%$ & $n$ & $\%$ & $n$ & $\%$ & $n$ & $\%$ & $\chi_{(d f)}^{2}$ & $P$ & $P$ & $|h|$ & $P$ & $|h|$ & $P$ & $|h|$ \\
\hline${ }^{\mathrm{a}}$ Risk of relapses & & 32 & $16.7 \%$ & 19 & $16.1 \%$ & 9 & $14.5 \%$ & 4 & $33.3 \%$ & $2.63_{(2)}$ & 0.268 & 0.780 & 0.04 & 0.138 & $0.52^{\dagger}$ & 0.117 & $0.51^{\dagger}$ \\
\hline
\end{tabular}

$\mathrm{SD}=$ standard deviation; $\alpha=$ Cronbach's alpha in the sample; $\mathrm{df}=$ degrees of freedom.

${ }^{*}$ Significant comparison (0.05 level). ${ }^{\dagger}$ Bold: effect size in the mild-moderate range $(|d|>0.50$ or $|h|>0.50)$ to high-large range $(|d|>0.80$ or $|h|>0.80)$.

${ }^{a}$ Relapse was considered for the presence of any gambling episode during which the patients make some kind of bet. 
The second objective of this work was to identify variables with the capacity to differentiate between the empirical trajectories, since this finding also provides evidence about the reliability and validity of the latent classes. Our results show that during young adulthood, socioeconomic position, GD severity at baseline, psychopathological state, and specific personality traits achieved discriminative capacity to differentiate between GD response trajectories during the next 6 months after the therapy. As a whole, our results are consistent with previous studies, which found that worse recovery after CBT was related to low education levels, low socioeconomic status, higher gambling symptom severity, or emotional distress (Dunn et al., 2012). These variables related to the resistance to the CBT programs have also been previously related to a higher risk of relapses (Challet-Bouju et al., 2017; Smith et al., 2015), which was also a variable with discriminative capacity on the empirical trajectories.

In our study, the personality profile defining the worst response trajectory to CBT was characterized by high harm avoidance and low self-directedness. This profile would be suggestive of patients with excessive worrying, marked tendencies toward pessimism and apprehension, drive to react to current circumstances and immediate needs, clear lack of self-direction in targets and objectives, ineffectiveness in solving problems, usually with feelings of general dissatisfaction and low levels of motivation. These characteristics have been typically found in subjects more prone to developing increased anxiety and depression during their lives (Bajraktarov, Gudeva-Nikovska, Manuševa, \& Arsova, 2017; Kampman, Viikki, Järventausta, \& Leinonen, 2014). Moreover, this specific personality profile has been described in most dysfunctional impulsivityrelated disorders as well (Claes et al., 2012; del PinoGutiérrez et al., 2017), and, in general, these traits have been considered as powerful predictors of the maintenance and continuation of dysfunctional behaviors despite therapeutic interventions (Ociskova, Prasko, Latalova, Kamaradova, \& Grambal, 2016). It has been hypothesized that this persistence in behaviors related to high harm avoidance and low self-directedness is due to the patients' reluctance to deal with stressful situations and their affectation in self-perceived wellness and happiness (C. Robert Cloninger \& Zohar, 2011). In other words, it would be individuals with difficulties in dealing with their negative emotional states who would self-regulate in a dysfunctional way through strategies of avoidance and escape, such as gambling. Our results related to the relevance of personality traits in defining response trajectories for GD are in line with those of the few follow-up studies examining the long-term effects of treatment programs on such patients, which found the relevance of personality traits for predicting abstinence at six-month and one-year follow-ups (Müller et al., 2017; Ramos-Grille, Gomà-iFreixanet, Aragay, Valero, \& Vallès, 2013). Finally, some studies exploring the association between therapeutic outcomes and personality traits from Cloninger's biopsychosocial model of personality have concluded that the two traits most significantly connected to self-stigma (high harm avoidance and low self-directedness) are also the most predictive of treatment outcomes (the other five personality traits relate only slightly or not at all to therapy results) (Bajraktarov et al., 2017). These results, however, must be interpreted with caution, since while self-stigma has been widely researched for many mental health conditions (Livingston \& Boyd, 2010), few studies have analyzed correlates for self-stigma in the problem gambling area. Available research suggests that fears related to the gambling activity, feelings of shame, guilt, weakness and embarrassment of being perceived as a "problem gambler" could lead to GD patients to keep their activity a secret, avoiding disclosure and considering the results of their behavior as low-efficient (Hing \& Russell, 2017), which together can lead to an increase in self-stigma. One would hypothesize that patients with high scores in the temperament trait of harm-avoidance should be characterized by excessive worrying, shyness in social contact, fears, and tendency toward pessimism, which can be directly connected with a predisposition to psychiatric illness (including GD) and the consequent higher levels of stigmatization. Low levels of self-directedness would be characteristic of patients with a low ability to regulate and adapt their behavior to the requirements of the situation and with difficulties in selfacceptance, and this profile is also highly vulnerable to developing mental illness and higher self-stigma.

Finally, the results of our study outlining the predictive capacity of high GD and psychopathological state at baseline on the worst therapeutic trajectory are also consistent with empirical evidence reported in the literature. For example, the study by Merkouris and colleagues found that low levels of gambling problems, accompanied by low depression scores and low scores in novelty seeking, were the baseline factors most strongly related to better outcome at post-therapy and follow-up (Merkouris et al., 2016). The research published by Maniaci and colleagues also outlines that gambling severity and high comorbidity were significant predictors of poor early therapeutic outcomes (Maniaci et al., 2017).

\section{Limitations and strengths}

There are three main research limitations in this study that could impact the empirical evidence and results. First, since data correspond to a short-term follow-up time after the therapy (6 months), the response trajectories could be nonrepresentative for a longer period (there is no way of guaranteeing that the empirical classes will persist over time). Second, all the patients who completed the CBT and fulfilled the inclusion criteria were included in the statistical analysis, regardless of the presence of dropouts during the follow-up (the risk of dropping out was $28.6 \%$ in the study, which represents a risk consistent with studies in the gambling area). It must be argued, however, that completers and dropouts did not achieve statistical differences in the baseline (sociodemographic and clinical state) and that the procedure used in this study to identify the response trajectories (LCGA in Mplus-8) uses a full information method, which does not replace or impute missing data, but which instead handles incomplete 
information within the analysis using all the available information in the data set (this procedure has shown good reliability/validity in producing unbiased parameter estimates for missing data in these types of modeling [which usually treat longitudinal data with a relatively high percentage of missing values]). Third, one of the empirical trajectories included only $n=12$ participants, which affects the statistical power to assess its potential predictive factors. It must be considered, however, that one of the characteristics of the LCGA is its capacity to identify even groups of patients who represent rare/infrequent clinical conditions with adequate reliability/ validity. In this study, the three-class model achieved adequate goodness of fit, and the emergence of this trajectory should be considered of high clinical relevance since it grouped patients with the worst longitudinal recovery. To allow the identification of the potential variables explaining the recovery trajectories, this study includes both significance tests and standardized measures of the effect size that are independent of the sample sizes (Cohen's- $d$ and Cohen's- $h$ coefficients). Fourth, the results can be generalized only to GD men: women were not considered in this study because the low sample size of gambling disordered females in our treatment unit and the differences in the CBT programs (depending on the patients' sex) could become a source of bias leading to incorrect results and conclusions. Fifth, the lack of a control group in this work does not allow attributing the empirical trajectories of the LCGA to reliable phenotypes/responses to the CBT program. Control groups are needed for discriminating between treatment outcomes from other factors, such as the natural history of a disease or even the researchers' or patients' expectations. It must be stated that a no-treatment group was not ethically reasonable in our work because adequate care for GD has been well clinically established for CBT and potential alternatives (such as waiting-lists) were not possible in our treatment unit. Finally, the comparison between the empirical trajectories was performed for a limited number of measures. Although this study includes all the variables available in the complete sample, considering more characteristics informing on other gambling related variables (such as the neuropsychological functioning and additional features of gambling beyond severity) would have been relevant to provide a complete picture of the empirical classes.

Strengths of this study include the analysis of longitudinal data (from baseline to 6-month follow-up after therapy) in a large sample of young and young-adult GD patients. Strength of this work is its statistical methodological approach, which combines person-centered and variable-level techniques. Traditionally, the study of the effectiveness of the therapeutic plans to treat GD has been focused on variable-centered methods, focused on exploring and describing the relationships between the potential predictors and the therapeutic outcomes, and which have the distinctive feature of considering the patients as a group, isolating the significant clinical features in which individuals differ (these methods operate based on the analysis of the potential correlational structure of the variables, their stability over time, and their predictive capacity for predetermined criteria). Therefore, variable-level approaches do not provide information on person-specific (intra-individual) clinical dynamics states. In contrast, person-centered approaches (such as the identification of response trajectories) start from the grouping of individuals according to their own responses (in our study, the evolution of gambling problem severity) and focus attention on the intra-individual structure of variables (the individual is conceived as a whole and not as the sum of isolated features). The use of LCGA is common in some medical areas, for example, in pediatric studies, which analyze longitudinal data series with the aim of describing courses of children's functioning based on specific childhood outcomes (usually named "developmental trajectories"). The results obtained in these studies provide therapists and families with robust resources to evaluate the clinical deviation of a child's performance/behavior based on the distance observed in relation to other children of similar ages and/or functional ability levels. With the increase in the number and scope of longitudinal research studies, the number of strategies for analyzing prospective data has also expanded, and various medical areas now employ longitudinal analytical techniques such as LCGA. Nonetheless, to our knowledge, few studies have addressed the study of GD based on the identification of response/course trajectories, and the published research employing these techniques has examined the natural history of untreated problem gamblers, largely at young ages. Therefore, gambling severity trajectories obtained in this study should be considered as being well suited for addressing questions that concern individual differences in clinical profiles, their response trajectories and their correlates. These results also put forward future lines of research on gambling progression after therapeutic clinical interventions and about the risk factors for poor response to therapy in young and young-adult gambling samples.

\section{CONCLUSIONS}

Our results have implications in both the measurement and the intervention areas. The patient profile most strongly related to poor treatment trajectory in our study includes gambling severity and higher general psychopathology at baseline, as well as harm avoidance and self-directedness traits. Effectiveness measurement and managing of these features could prevent therapy resistance and thereby help prevent individuals from entering the vicious circle of chronic gambling, suffering, and disability.

Funding: We thank the CERCA Programme/Generalitat de Catalunya for institutional support. This manuscript and research were supported by grants from the Ministerio de Economía y Competitividad (PSI2015-68701-R). The research was funded by the Delegación del Gobierno para el Plan Nacional sobre Drogas (2017I067 and 2019I47), Instituto de Salud Carlos III (ISCIII) (FIS PI14/00290 and PI17/ 01167) and co-funded by FEDER funds/European Regional Development Fund (ERDF), a way to build Europe. CIBERobn and CIBERSAM are both initiatives of ISCIII. The study received the support of the Secretariat for Universities 
and Research of the Ministry of Business and Knowledge of the Government of Catalonia. TMM and MLM are supported by a predoctoral Grant of the Ministerio de Educación, Cultura y Deporte (FPU16/02087; FPU15/02911).

Author contributions: Conceptualization, Fernando FernándezAranda and Susana Jiménez-Murcia; Data curation, Roser Granero; Funding acquisition, Fernando Fernández-Aranda; Investigation, Mónica Gómez-Peña, Laura Moragas, Teresa Mena-Moreno, Amparo del Pino-Gutiérrez, Ester Codina, Gemma Casalé, Isabel Baenas-Soto, Eduardo ValencianoMendoza, Bernat Mora-Maltas, Isabel Sánchez and María Lozano-Madrid; Methodology, Roser Granero, Virginia Martín-Romera and Zaida Agüera; Project administration, José M. Menchón and Susana Jiménez-Murcia; Supervision, Susana Jiménez-Murcia; Writing - original draft, Roser Granero and Susana Valero-Solis; Writing - review \& editing, Fernando Fernández-Aranda, Virginia Martín-Romera, Zaida Agüera and Isabel Sánchez.

Conflict of interest: The authors declare no conflict of interest. The funders had no role in the design of the study; in the collection, analyses, or interpretation of data; in the writing of the manuscript; or in the decision to publish the results.

\section{REFERENCES}

Abbott, M. W. (2019). Professionally delivered interventions for gambling disorder. Current Opinion in Psychiatry, 32(4), 313-319. https://doi.org/10.1097/YCO.0000000000000516.

American Psychiatric Association. (2000). Diagnostic and statistical manual of mental disorders (4th ed.). Washington D.C.: Author.

American Psychiatric Association. (2013). Diagnostic and statistical manual of mental disorders (5th ed.). Washington D.C.: Author.

An, H., He, R.-H., Zheng, Y.-R., \& Tao, R. (2017). Cognitivebehavioral therapy. Advances in Experimental Medicine and Biology, 1010, 321-329. https://doi.org/10.1007/978-981-105562-1_16.

Aragay, N., Jiménez-Murcia, S., Granero, R., Fernández-Aranda, F., Ramos-Grille, I., Cardona, S., et al. (2015). Pathological gambling: Understanding relapses and dropouts. Comprehensive Psychiatry, 57, 58-64. https://doi.org/10.1016/j.comppsych.2014. 10.009 .

Babić, R., Babić, D., Martinac, M., Pavlovic, M., Vasilj, I., Miljko, M., et al. (2018). Addictions without drugs: Contemporary addictions or way of life?. Psychiatria Danubina, 30(Suppl. 6), 371-379.

Bajraktarov, S., Gudeva-Nikovska, D., Manuševa, N., \& Arsova, S. (2017). Personality characteristics as predictive factors for the occurrence of depressive disorder. Open Access Macedonian Journal of Medical Sciences, 5(1), 48-53. https://doi.org/ 10.3889/oamjms.2017.022.

Banz, B. C., Yip, S. W., Yau, Y. H. C., \& Potenza, M. N. (2016). Behavioral addictions in addiction medicine: From mechanisms to practical considerations. Progress in Brain Research, 223, 311-328. https://doi.org/10.1016/bs.pbr.2015.08.003.
Blaszczynski, A., \& Nower, L. (2002). A pathways model of problem and pathological gambling. Addiction, 97(5), 487-499. https://doi.org/10.1046/j.1360-0443.2002.00015.x.

Calado, F., Alexandre, J., \& Griffiths, M. D. (2017). Prevalence of adolescent problem gambling: A systematic review of recent research. Journal of Gambling Studies, 33(2), 397-424. https:// doi.org/10.1007/s10899-016-9627-5.

Calado, F., \& Griffiths, M. D. (2016). Problem gambling worldwide: An update and systematic review of empirical research (20002015). Journal of Behavioral Addictions, 5(4), 592-613. https:// doi.org/10.1556/2006.5.2016.073.

Challet-Bouju, G., Bruneau, M., IGNACE Group, C., Victorri-Vigneau, C., \& Grall-Bronnec, M. (2017). Cognitive remediation interventions for gambling disorder: A systematic review. Frontiers in Psychology, 8, 1961. https://doi.org/10.3389/fpsyg.2017.01961.

Claes, L., Jimenez-Murcia, S., Agüera, Z., Sánchez, I., Santamaría, J., Granero, R., et al. (2012). Eating disorders and pathological gambling in males: Can they be differentiated by means of weight history and temperament and character traits?. Eating Disorders, 20(5), 395-404. https://doi.org/10.1080/10640266. 2012.715517.

Cloninger, C. R., \& Zohar, A. H. (2011). Personality and the perception of health and happiness. Journal of Affective Disorders, 128(1-2), 24-32. https://doi.org/10.1016/j.jad.2010.06.012.

Cloninger, C. R. (1999). The temperament and character inventoryrevised. St Louis, MO: Center for Psychobiology of Personality, Washington University.

Cowlishaw, S., Merkouris, S., Dowling, N., Anderson, C., Jackson, A., \& Thomas, S. (2012). Psychological therapies for pathological and problem gambling. Cochrane Database of Systematic Reviews, 11, CD008937. https://doi.org/10.1002/14651858. CD008937.pub2.

del Pino-Gutiérrez, A., Jiménez-Murcia, S., Fernández-Aranda, F., Agüera, Z., Granero, R., Hakansson, A., et al. (2017). The relevance of personality traits in impulsivity-related disorders: From substance use disorders and gambling disorder to bulimia nervosa. Journal of Behavioral Addictions, 6(3), 396-405. https://doi.org/10.1556/2006.6.2017.051.

Derogatis, L. R. (1994). SCL-90-R: Symptom checklist-90-R. Administration, scoring, and procedures manuall-II for the revised version. Towson, MD: Clinical Psychometric Research.

Derogatis, L. R. (1997). SCL-90-R. Cuestionario de 90 síntomas [90 symptoms questionnaire]. Madrid: TEA Ediciones.

Devos, M. G., Clark, L., Bowden-Jones, H., Grall-Bronnec, M., Challet-Bouju, G., Khazaal, Y., et al. (2020). The joint role of impulsivity and distorted cognitions in recreational and problem gambling: A cluster analytic approach. Journal of Affective Disorders, 260, 473-482. https://doi.org/10.1016/j.jad.2019.08. 096.

Dunn, K., Delfabbro, P., \& Harvey, P. (2012). A preliminary, qualitative exploration of the influences associated with dropout from cognitive-behavioural therapy for problem gambling: An Australian perspective. Journal of Gambling Studies, 28(2), 253-272. https://doi.org/10.1007/s10899-011-9257-x.

Echeburúa, E., Báez, C., Fernández, J., \& Páez, D. (1994). Cuestionario de juego patológico de South Oaks (SOGS): Validación española [South Oaks Gambling Screen (SOGS): Spanish 
validation]. Análisis de Modificación de Conducta [Behavior Modification Analysis], 20, 769-791.

Enders, C. K., \& Bandalos, D. L. (2001). The relative performance of full information maximum likelihood estimation for missing data in structural equation models. Structural Equation Modeling, 8(3), 430-457. https://doi.org/10.1207/S15328007SEM0803_5.

Gainsbury, S. M., Russell, A., Blaszczynski, A., \& Hing, N. (2015). The interaction between gambling activities and modes of access: A comparison of internet-only, land-based only, and mixed-mode gamblers. Addictive Behaviors, 41, 34-40. https:// doi.org/10.1016/j.addbeh.2014.09.023.

Gómez-Peña, M., Penelo, E., Granero, R., Fernández-Aranda, F., Álvarez-Moya, E., Santamaría, J. J., et al. (2012). Correlates of motivation to change in pathological gamblers completing cognitive-behavioral group therapy. Journal of Clinical Psychology, 68(7), 732-744. https://doi.org/10.1002/jclp.21867.

Gooding, P., \& Tarrier, N. (2009). A systematic review and metaanalysis of cognitive-behavioural interventions to reduce problem gambling: Hedging our bets?. Behaviour Research and Therapy, 47(7), 592-607. https://doi.org/10.1016/j.brat.2009.04.002.

Graham, J. W. (2009). Missing data analysis: Making it work in the real world. Annual Review of Psychology, 60(1), 549-576. https://doi.org/10.1146/annurev.psych.58.110405.085530.

Grande-Gosende, A., López-Núñez, C., García-Fernández, G., Derevensky, J., \& Fernández-Hermida, J. R. (2019). Systematic review of preventive programs for reducing problem gambling behaviors among young adults. Journal of Gambling Studies (in press). https://doi.org/10.1007/s10899-019-09866-9.

Gutiérrez-Zotes, J. A., Bayón, C., Montserrat, C., Valero, J., Labad, A., Cloninger, C. R., et al. (2004). Temperament and Character Inventory Revised (TCI-R). Standardization and normative data in a general population sample. Actas Españolas de Psiquiatria [Spanish Minutes of Psychiatry], 32(1), 8-15. Retrieved from http://www.ncbi.nlm.nih.gov/pubmed/14963776.

Hing, N., \& Russell, A. M. T. (2017). Psychological factors, sociodemographic characteristics, and coping mechanisms associated with the self-stigma of problem gambling. Journal of Behavioral Addictions, 6(3), 416-424. https://doi.org/10.1556/2006.6.2017.056.

Hollingshead, A. B. (2011). Four factor index of social status. Yale Journal of Sociology, 8, 21-51.

Ioannidis, K., Hook, R., Wickham, K., Grant, J. E., \& Chamberlain, S. R. (2019). Impulsivity in gambling disorder and problem gambling: A meta-analysis. Neuropsychopharmacology: Official Publication of the American College of Neuropsychopharmacology, 44(8), 1354-1361. https://doi.org/10.1038/s41386-019-0393-9.

Jiménez-Murcia, S., Del Pino-Gutiérrez, A., Fernández-Aranda, F., Granero, R., Hakänsson, A., Tárrega, S., et al. (2016). Treatment outcome in male gambling disorder patients associated with alcohol use. Frontiers in Psychology, e-7:465. https://doi.org/10. 3389/fpsyg.2016.00465.

Jiménez-Murcia, S., Granero, R., Fernández-Aranda, F., Arcelus, J., Aymamí, M. N., Gómez-Peña, M., et al. (2015). Predictors of outcome among pathological gamblers receiving cognitive behavioral group therapy. European Addiction Research, 21(4), 169-178. https://doi.org/10.1159/000369528.

Jiménez-Murcia, S., Stinchfield, R., Álvarez-Moya, E., Jaurrieta, N., Bueno, B., Granero, R., et al. (2009). Reliability, validity, and classification accuracy of a Spanish translation of a measure of
DSM-IV diagnostic criteria for pathological gambling. Journal of Gambling Studies, 25(1), 93-104. https://doi.org/10.1007/ s10899-008-9104-x.

Jiménez-Murcia, S., Tremblay, J., Stinchfield, R., Granero, R., Fernández-Aranda, F., Mestre-Bach, G., et al. (2017). The involvement of a concerned significant other in gambling disorder treatment outcome. Journal of Gambling Studies, 33(3), 937-953. https://doi.org/10.1007/s10899-016-9657-z.

Jiménez-Murcia, Susana, Álvarez-Moya, E. M., Granero, R., Aymami, M. N., Gómez-Peña, M., Jaurrieta, N., et al. (2007). Cognitive-behavioral group treatment for pathological gambling: Analysis of effectiveness and predictors of therapy outcome. Psychotherapy Research, 17, 544-552. https://doi.org/ 10.1080/10503300601158822.

Jiménez-Murcia, Susana, Aymamí, M. N., Gómez-Peña, M., Álvarez-Moya, E. M., \& Vallejo, J. (2006). Protocols de tractament cognitiuconductual pel joc patologic i d'altres addicions no toxiques [Guidelines of cognitive-behavioral treatment of pathological gambling and other non-toxic addicitions]. Barcelona, Spain: Hospital Universitari de Bellvitge, Departament de Salut, Generalitat de Catalunya.

Jiménez-Murcia, Susana, Del Pino-Gutiérrez, A., FernándezAranda, F., Granero, R., Hakänsson, A., Tárrega, S., et al. (2016). Treatment outcome in male gambling disorder patients associated with alcohol use. Frontiers in Psychology, e-7, 465. https://doi.org/10.3389/fpsyg.2016.00465.

Jiménez-Murcia, Susana, Granero, R., Fernández-Aranda, F., Arcelus, J., Aymamí, M. N., Gómez-Peña, M., et al. (2015). Predictors of outcome among pathological gamblers receiving cognitive behavioral group therapy. European Addiction Research, 21(4), 169-178. https://doi.org/10.1159/000369528.

Kampman, O., Viikki, M., Järventausta, K., \& Leinonen, E. (2014). Meta-analysis of anxiety disorders and temperament. Neuropsychobiology, 69(3), 175-186. https://doi.org/10.1159/000360738.

Kelley, K., \& Preacher, K. J. (2012). On effect size. Psychological Methods, 17(2), 137-152. https://doi.org/10.1037/a0028086.

Ledgerwood, D. M., \& Petry, N. M. (2010). Subtyping pathological gamblers based on impulsivity, depression, and anxiety. Psychology of Addictive Behaviors: Journal of the Society of Psychologists in Addictive Behaviors, 24(4), 680-688. https://doi. org/10.1037/a0019906.

Lesieur, H. R., \& Blume, S. B. (1987). The South Oaks Gambling Screen (SOGS): A new instrument for the identification of pathological gamblers. American Journal of Psychiatry, 144(9), 1184-1188. https://doi.org/10.1176/ajp.144.9.1184.

Livingston, J. D., \& Boyd, J. E. (2010). Correlates and consequences of internalized stigma for people living with mental illness: A systematic review and meta-analysis. Social Science \& Medicine (1982), 71(12), 2150-2161. https://doi.org/10.1016/j.socscimed.2010.09.030.

Lo, Y., Mendell, N., \& Rubin, D. (2001). Testing the number of components in a normal mixture. Biometrika, 88, 767-778. https://doi.org/10.1093/biomet/88.3.767.

Mallorquí-Bagué, N., Mestre-Bach, G., Lozano-Madrid, M., Fernandez-Aranda, F., Granero, R., Vintró-Alcazaz, C., et al. (2018). Trait impulsivity and cognitive domains involving impulsivity and compulsivity as predictors of gambling disorder treatment response. Addictive Behaviors, 87, 169-176. https:// doi.org/10.1016/j.addbeh.2018.07.006. 
Maniaci, G., La Cascia, C., Picone, F., Lipari, A., Cannizzaro, C., \& La Barbera, D. (2017). Predictors of early dropout in treatment for gambling disorder: The role of personality disorders and clinical syndromes. Psychiatry Research, 257, 540-545. https:// doi.org/10.1016/j.psychres.2017.08.003.

Merkouris, S. S., Thomas, S. A., Browning, C. J., \& Dowling, N. A. (2016). Predictors of outcomes of psychological treatments for disordered gambling: A systematic review. Clinical Psychology Review, 48, 7-31. https://doi.org/10.1016/j.cpr.2016.06.004.

Milosevic, A., \& Ledgerwood, D. M. (2010). The subtyping of pathological gambling: A comprehensive review. Clinical Psychology Review, 30(8), 988-998. https://doi.org/10.1016/j.cpr. 2010.06.013.

Moon, M., Lister, J. J., Milosevic, A., \& Ledgerwood, D. M. (2017). Subtyping non-treatment-seeking problem gamblers using the pathways model. Journal of Gambling Studies, 33(3), 841-853. https://doi.org/10.1007/s10899-016-9658-y.

Müller, K. W., Wölfling, K., Dickenhorst, U., Beutel, M. E., Medenwaldt, J., \& Koch, A. (2017). Recovery, relapse, or else? Treatment outcomes in gambling disorder from a multicenter follow-up study. European Psychiatry: The Journal of the Association of European Psychiatrists, 43, 28-34. https://doi.org/ 10.1016/j.eurpsy.2017.01.326.

Nower, L., Martins, S. S., Lin, K. -H., \& Blanco, C. (2013). Subtypes of disordered gamblers: Results from the national epidemiologic survey on alcohol and related Conditions. Addiction (Abingdon, England), 108(4), 789-798. https://doi.org/10.1111/ add.12012.

Nylund, K. L., Asparouhov, T., \& Muthén, B. O. (2007). Deciding on the number of classes in latent class analysis and growth mixture modeling: A Monte Carlo simulation study. Structural Equation Modeling, 14(4), 535-569. https://doi.org/10.1080/ 10705510701575396.

Ociskova, M., Prasko, J., Latalova, K., Kamaradova, D., \& Grambal, A. (2016). Psychological factors and treatment effectiveness in resistant anxiety disorders in highly comorbid inpatients. Neuropsychiatric Disease and Treatment, 12, 1539-1551. https://doi.org/10.2147/NDT.S104301.

Peter, S. C., Brett, E. I., Suda, M. T., Leavens, E. L. S., Miller, M. B., Leffingwell, T. R., et al. (2019). A meta-analysis of brief personalized feedback interventions for problematic gambling. Journal of Gambling Studies, 35(2), 447-464. https://doi.org/10. 1007/s10899-018-09818-9.

Petry, N. M. (2002). A comparison of young, middle-aged, and older adult treatment-seeking pathological gamblers. The
Gerontologist, 42(1), 92-99. Retrieved from http://www.ncbi. nlm.nih.gov/pubmed/11815703.

Petry, N. M., Ginley, M. K., \& Rash, C. J. (2017). A systematic review of treatments for problem gambling. Psychology of Addictive Behaviors, 31(8), 951-961. https://doi.org/10.1037/adb0000290.

Ramos-Grille, I., Gomà-i-Freixanet, M., Aragay, N., Valero, S., \& Vallès, V. (2013). The role of personality in the prediction of treatment outcome in pathological gamblers: A follow-up study. Psychological Assessment, 25(2), 599-605. https://doi.org/ 10.1037/a0031930.

Rash, C. J., \& Petry, N. M. (2014). Psychological treatments for gambling disorder. Psychology Research and Behavior Management, 7, 285-295. https://doi.org/10.2147/PRBM.S40883.

Simes, R. J. (1986). An improved bonferroni procedure for multiple tests of significance. Biometrika, 73(3), 751-754. https://doi.org/ 10.1093/biomet/73.3.751.

Smith, D. P., Battersby, M. W., Pols, R. G., Harvey, P. W., Oakes, J. E., \& Baigent, M. F. (2015). Predictors of relapse in problem gambling: A prospective cohort study. Journal of Gambling Studies, 31(1), 299-313. https://doi.org/10.1007/s10899-0139408-3.

Stinchfield, R. (2003). Reliability, validity, and classification accuracy of a measure of DSM-IV diagnostic criteria for pathological gambling. American Journal of Psychiatry, 160(1), 180-182. https://doi.org/10.1176/appi.ajp.160.1.180.

Tárrega, S., Castro-Carreras, L., Fernández-Aranda, F., Granero, R., Giner-Bartolomé, C., Aymamí, N., et al. (2015). A serious videogame as an additional therapy tool for training emotional regulation and impulsivity control in severe gambling disorder. Frontiers in Psychology, 6, 1721. https://doi.org/10.3389/fpsyg. 2015.01721.

Tolchard, B. (2017). Cognitive-behavior therapy for problem gambling: a critique of current treatments and proposed new unified approach. Journal of Mental Health (Abingdon, England), 26(3), 283-290. https://doi.org/10.1080/09638237.2016. 1207235.

van de Schoot, R., Sijbrandij, M., Winter, S. D., Depaoli, S., \& Vermunt, J. K. (2017). The GRoLTS-checklist: Guidelines for reporting on latent trajectory studies. Structural Equation Modeling: A Multidisciplinary Journal, 24(3), 451467. https://doi.org/10.1080/10705511.2016.1247646.

Zou, Z., Wang, H., d'Oleire Uquillas, F., Wang, X., Ding, J., \& Chen, H. (2017). Definition of substance and non-substance addiction. Advances in Experimental Medicine and Biology, 1010, 21-41. https://doi.org/10.1007/978-981-10-5562-1_2.

This is an open-access article distributed under the terms of the Creative Commons Attribution-NonCommercial 4.0 International License (https://creativecommons.org/ licenses/by-nc/4.0/), which permits unrestricted use, distribution, and reproduction in any medium for non-commercial purposes, provided the original author and source are credited, a link to the CC License is provided, and changes - if any - are indicated. 